\title{
Retraction Notice: H. Yahyanejad and E. Shabanirad, Lukács and Reflection Theory, International Letters of Social and Humanistic Sciences, Vol. 61, pp. 145-154, 2015
}

\section{Editorial office of International Letters of Social and Humanistic Sciences}

\author{
Seestrasse 24c, CH-8806 Bach, Switzerland \\ ilshs@scipress.com
}

This article has been retracted at the request of the Publisher's representative.

The article [1] has been proven to be a duplicate of the publication [2].

The manuscript [2] was published in the journal The AnaChronisT in ine year 4 wh le in International Letters of Social and Humanistic Sciences in 2015 [1]. Thy the ar cle wa rojected to retraction to eliminate the redundant publication and discouraging forts $n$ duplicate publication malpractice.

The editors would like to apologize to the Journal's rea ers the late ase detection. We tend to publish original scientific manuscripts only.

We sincerely appreciate the efforts of anyone wb brings such ma ers to our attention. The author of [1] have been informed about the decision o retract th article [1] and agreed to the retraction. Thus, the paper has been declared retracted marked/ccordingly.

\section{References}

[1] H. Yahyanejad and E. Shabanirad, Lukác nd R 1lection Theory, International Letters of Social and nd Hum? ciences, DOI: 10.18052/www.scipre com/2 LHS.61 45

[2] Taek-Gwang Lee, The 10 (2004) 61-79. 